Institute of $\mathbf{F}_{\text {ood and }} \mathbf{A}$ gricultural $\mathbf{S}_{\text {ciences }}$

\title{
Florida Dairy Farm Situation and Outlook 20031
}

\author{
Russ Giesy, Albert de Vries, Michael Zylstra, Richard Kilmer, Dave Bray, Dan Webb²
}

\section{Situation}

Dairy farming is an important part of Florida's agricultural industry. Milk and cattle sales from dairies contributed about $\$ 459$ million to Florida's economy in 2001, about $\$ 45$ million more than in 2000.

The Florida Agricultural Statistics Service has indicated that there were about 152,000 cows on 209 dairy farms at the start of 2002. That reflects a decline of 3,000 cows from the start of 2001. However, the number of cows has been fairly consistent since 1996.

The Dairy Business Analysis Program (DBAP) is a cooperative effort of the Universities of Florida and Georgia, Southeast Milk Inc., and Southeast Dairy Herd Improvement Association (DHIA). This project annually surveys participating dairy farms relative to levels of revenues, expenses, and investments. DBAP data of 2001 showed that the average mailbox milk price received was $\$ 18.27$. The total revenues were $\$ 20.25$, total expenses were $\$ 17.61$ and net farm income was \$2.14. This level of profitability was second only to that set in 1999 in the DBAP series since 1995. However, 2002 data is expected to show financial performance similar to 1995, the poorest year of the DBAP series. Milk prices had fallen about $\$ 4$ in late 2001 and remained about \$16 through 2002.

In addition, the 2001 average price per head for replacement cows was $\$ 1,800$, up from $\$ 1,460$ in 2000 .

Driven by a slight increase in cow numbers $(0.21 \%)$ and a continued increase in milk per cow $(2.45 \%)$, milk production in the United States increased $2.72 \%$ from 2001 to 2002.

Despite a $0.89 \%$ increase in production per cow, Florida milk production decreased by an estimated $1.3 \%$ due to the $2.6 \%$ decrease in cow numbers in 2002.

\section{Outlook}

The national herd is expected to decrease by $0.87 \%$ while milk per cow is expected to increase by $1.99 \%$ in 2003 . The USDA forecasts a $1.24 \%$ increase in total US milk production in 2003.

1. This document is AN138, one of a series of the Department of Animal Sciences, Florida Cooperative Extension Service, Institute of Food and Agricultural Sciences, University of Florida. Published February 2003. Please visit the EDIS Web Site at http://edis.ifas.ufl.edu.

2. Russ Giesy, Multi-County Dairy Agent III, Sumter County; Albert de Vries, Assistant Professor, Department of Animal Sciences, University of Florida; Michael Zylstra, Graduate Student, University of Florida; Richard Kilmer, Professor, Department of Food and Resource Economics, University of Florida; Dave Bray, Extension Agent IV, Department of Animal Sciences, University of Florida; Dan Webb, Professor, Department of Animal Sciences, University of Florida; Florida Cooperative Extension Service, Institute of Food and Agricultural Sciences, University of Florida, Gainesville, 32611. 
Lower forecasted milk prices are expected to further reduce Florida's dairy herd, while milk per cow is expected to increase, yielding a slight decrease in the Florida milk supply in 2003.

Milk prices at the farm are likely to increase only slightly in the first two quarters of 2003. Forecasters suggest the possibility of a significant improvement during the third quarter due to an improved overall U.S. economy. Demand should increase $1 \%$ for fluid milk and 3\% for cheese. Butter is expected to be in short supply by fall. Meanwhile, milk supply is expected to remain the same or slightly decline, since a reduction in cow numbers is predicted. Also, milk per cow is expected to decrease slightly due to higher feed prices. Mailbox milk price received by Florida's producers may rebound to the $\$ 17$ to $\$ 18$ level in the last quarter of 2003, depending upon these demand-supply indicators.

\section{Background Information - the Challenge of Dairying in Florida}

\section{Production Challenges}

Florida's warm and humid climate is not ideal for dairy cattle that evolved during centuries of selective breeding in the relatively moderate climates of northern Europe. Heat stress has been shown to reduce production by $25 \%$ by reducing feed intake and increasing health problems such as mastitis, lameness and reproductive delay. Mastitis has been estimated to cost producers at least \$300/cow/year. Udder, feet and reproductive health challenges cause the culling of nearly $30 \%$ of cows each year. Higher replacement costs prohibit some dairies from culling the less productive animals, and this lowers total herd production and profitability.

\section{Economic Challenges}

Florida's dairy producers operate under a difficult economic situation. Despite a geographic difference and a product that's difficult to transport, they increasingly compete in a national and international marketplace. Negotiating consistently profitable milk prices has become increasingly difficult for Florida's dairy cooperative because larger handlers from outside the southeast are pushing to gain market share. Ultimately they would like to control Florida's growing market with its high fluid use and resulting higher price.

Milk price volatility has made the dairy farm economic situation in the 1990s challenging. DBAP data has shown that milk prices ranged from $\$ 15.51$ in 1995 to $\$ 18.56$ in 1998 , averaging $\$ 17.41$ from 1995-2001. Price volatility continues to create difficulties for producers since costs of production are much less variable than milk prices. The same DBAP-participating dairies averaged \$17.61 total expense per cwt. from 1995-2001. This is about $25 \%$ higher than a national average.

The size of Florida's dairies requires large investments, over $\$ 1.5$ million on average. But the return to invested capital is generally insufficient. The DBAP-participating dairies' average return on assets ranged from $0 \%$ in 1995 to $9 \%$ in 2001 . This rate of return discourages new investments. Florida lost a third of its dairy farms in the 1990s.

\section{Environmental Challenges}

Dairies face increased regulation due to social pressure. Larger herds attract the attention of neighbors and activists concerned with odors, flies, and potential losses of nutrients that influence water quality.

The greatest reason for the environmental issues facing Florida dairy producers is the high concentration of animals on farmland. High producing cows may consume 100 pounds of feed and 50 gallons of water per day. They may excrete 195 pounds of manure and urine. Florida dairies average nearly 730 cows and about $50 \%$ of them raise young replacement cattle as well. Thus, there is an extremely high volume of nutrients flowing through the dairy system. Even minuscule percentages of these nutrients, if lost, could command attention of regulatory agencies. Further, if cow densities on land become fixed by regulatory action, new constraints on herd size will forever limit most farms' opportunity to grow, dooming them to eventual inefficiency and discontinuation.

The cost of nutrient handling systems that will meet the future requirements of environmental regulatory agencies is unknown and perceived to be a 
major constraint to dairies as they commit to the future. These costs have two parts; (a) the original investment costs of engineering and putting the new systems in place and (b) operating and maintaining the systems well into the future. These systems, incorporating significant levels of new technology, have been implemented to ensure that dairies efficiently handle nutrients in an environmentally-friendly manner. The UF/IFAS

Extension Service is helping to determine the cost of implementing and operating these new systems so as to aid management decisions for these dairies. Also, the information will be valuable to many others that have yet to develop their best responses to environmental regulation.

Size and location differences among dairies significantly affect nutrient handling system expense. Additionally, different types of systems have differing initial investment and operating expenses. Dairies that employ such new systems take on a competitive disadvantage since investing in these new systems generally does not generate a positive return. 